\title{
Memoria y migración laboral entre los totonaco del siglo XX
}

\author{
Iván Gerardo Bravo y Troncoso Deance ${ }^{1}$
}

RESUMEN: El texto retoma la tradición oral del grupo étnico de los totonacos para la reconstrucción de una parte de la memoria de la migración durante mediados del siglo XX. Se usan historias de vida, entrevistas a profundidad y el trabajo etnográfico para recabar la información de interés. Bajo el enfoque de la comunicación intercultural, se realiza narración de lo que la investigación a arrojado como relevante en torno a la necesidad de la migración laboral en la sierra entre los estados de Puebla y Veracruz en México.

Palabras clave: Memoria, comunicación intercultural, totonacos, historia oral, etnografía.

\section{Memória e migração laboral entre os totonaco do século xx}

RESUMO: O texto aborda a tradição oral do grupo étnico totonaco para a reconstrução de uma parte da memória da migração em meados do século XX. Histórias de vida, entrevistas em profundidade e trabalho etnográfico são usadas para reunir informações de interesse. Sob a abordagem da comunicação intercultural, é feita a narração do que a pesquisa mostrou relevante quanto à necessidade de migração trabalhista nas terras altas entre os estados de Puebla e Veracruz, no México.

Palavras-chave: Memória, comunicação intercultural, totonacos, história oral, etnografia.

\section{Memory and labor migration among the totonacs of the 20th century}

ABSTRACT: The text takes up the oral tradition of the Totonac ethnic group for the reconstruction of a part of the memory of migration during the middle of the 20th century. Life stories, indepth interviews and ethnographic work are used to gather information of interest. Under the intercultural communication approach, narration is made of what the research has shown to be relevant regarding the need for labor migration in the highlands between the states of Puebla and Veracruz in Mexico.

Keywords: Memory, intercultural communication, totonacs, oral history, ethnography.

\section{INTRODUCCIÓN}

Entre los pueblos que habitan la región denominada como Totonacapan en México, existe un sustento de la reproducción de la memoria histórica con base en la tradición oral. Los orígenes de diversos fenómenos de estudios en esta región, son remontados por sus habitantes a periodos vagos y difí-

\footnotetext{
${ }^{1}$ Profesor Investigador de la Benemérita Universidad Autónoma de Puebla, México. ivan@deance.org.mx ivan.deance@correo.buap.mx www.deance.org.mx www.imagenymemoria.buap.mx
}

cilmente sustentables de manera documental lo cual representa un desafío, sin embargo lo verdaderamente complejo es la reconstrucción de un periodo cercano a partir del uso indiscriminado de dos lenguas diferentes. En el desarrollo de varias entrevistas a profundidad e historias de vida en la región mencionada, es común que aparecieran palabras o conceptos en la lengua local, sin embargo esto comenzó a complejizarse con algunas personas que aparentemente son hablantes funcionales del español pero en realidad tienen grandes problemas de inter- 
ferencia lingüística.

Al principio de estas entrevistas se usó el idioma totonaco solo para referir términos específicos, pero conforme se avanzaba en la plática, a varios interlocutores les pareció más sencillo seguir la entrevista en su lengua materna. Lo anterior no parecería tan raro hasta que nos percatamos que nuestra comprensión de lo que se decía era poca, evidenciando que, más allá de tener variantes lingüísticas diferentes, nos encontrábamos frente a lenguas diferentes. Sortear esta novedosa realidad sin abandonar el trabajo de investigación representó un reto tan complicado como la misma diversidad lingüística en México y es en este contexto en el que se desarrolló el trabajo de investigación, a partir de las entrevistas bilingües, las transcripciones y las traducciones, buscando reconstruir el sentido de la narrativa con una prosa literaria que integrara las partes esenciales respaldadas por el trabajo etnográficos y los recorridos de campo. Al final, el texto que se produce es más que una transcripción o un sustrato del diario de campo y aquí se presenta.

\section{MIGRAR PARA SOBREVIVIR ${ }^{2}$}

Justo cuando sintió que lo iban a matar, Mariano sólo quiso recordar la silueta de los cerros que delineaban su pueblo y el olor a copal quemado con el que su madre lo había limpiado y bendecido ese amanecer en que decidió dejar Kalaxuxne para buscar diez pesos por jornal en una tierra lejana.

Era un niño delgado de 14 años, en esa época no existía la adolescencia, se era niño

\footnotetext{
2Entrevistas: dv05_ahs01_0101113, dv05_ahs02_0101114,dv05_msg01_0101113, dv05_msg02_0101114,dv05_msg03_0101115.
}

mientras uno no tenía mujer y se convertía en hombre al casarse o al encargar un hijo, cosas que muchas veces venía de la mano. Aun hoy día, en su lengua no hay una palabra para nombrar a los adolescentes; se es niño y responde uno cuando le nombran 'awasa ${ }^{3}$ o se es hombre y uno es nombrado chixkú ${ }^{4}$, así nomas. Por ese tiempo las carreteras no llegaban a la sierra, los arrieros con sus interminables recuas de burros y mulas eran los canales de comunicación y traslado de mercancías, pasar el río Cempoala representaba nadar o buscar algún cruce en balsa por una módica cantidad de dinero y la luz eléctrica era sólo un mito más, que llegaba en voz de algún pariente viajero o algún arriero platicón.

También había una terraplén que servía las veces de pista de aterrizaje a la maravilla moderna de la avioneta, la cual, tenía capacidad para traer hasta cinco personas o alguna carga que no le excediera en volumen y peso. El traslado en ella era caro pero muy útil, algunos personajes de la región que no podían caminar tanto como la gente del pueblo, decían que era indispensable.

Mariano disfrutaba de vivir en su pueblo. Kalaxuxne en los sesenta, parecía el mejor lugar para vivir. Trabajar con su papá en la milpa, acarrear leña para su mamá y cargar algunos cántaros desde el manantial para toda la familia, eran algunas de las tareas cotidianas que Mariano hacía sin reflexionar. No existía otro estilo de vida que imaginar y casi todas las horas del día se le iban en sus

\footnotetext{
3 Del totonaco: "niño". En el caso de la variante dialectal de "Mariano" no existe el fonema de la 'k' velar por lo que dicho sonido es suplido por una oclusión glotal, de tal modo que en variantes vecinas se les nombra qawasa. Para el caso de la interserrana puede ser pronunciado como kawasa o kavasa y hacia la huasteca este se modifica hasta kawacho.

${ }^{4}$ Del totonaco: "señor".
} 
deberes.

Sin embargo, el rumor traído por algunos migrantes decía que, a dos días de camino del río Cempoala, había gente contratando milperos a diez pesos el jornal, frente a los dos que con suerte se podían ganar en alguna finca cercana a Kalaxuxne.

Más allá del río eran tierras desconocidas para él; ya antaño había demostrado ser muy valiente como aquella vez que, acompañado de sus amigos, fue en busca de la piedra en forma de campaña que al golpearla sonaba como tal, o cuando se atrevió a cruzar de noche el puente tunkuwiní llamado también "puente del diablo" por haber sido cimentados los pilotes con la sangre y cuerpos de gente viva, razón por la cual nunca se caía ${ }^{5}$; sin embargo, Mariano no se armaba del suficiente valor para emprender solo un viaje lleno de tantas incertidumbres.

Pasaron muchas noches en las que no podía conciliar el sueño y pasada la media noche, dejaba la cobija sobre su cama de tablas y miraba por entre los huecos que dejaban los bejucos de tarro con los que estaba construida su casa. Miraba la luna; se preguntaba si se vería igual de luminosa desde aquellas tierras lejanas en las que pagaban a diez pesos el jornal y luego de agotar su curiosidad, se recostaba sobre los brazos cruzados en su nuca cual si fuesen almohadas y soñaba con lo que podría comprar para su madre con semejante for-

\footnotetext{
${ }^{5}$ Mito que se mantuvo cierto hasta la inundación de 1999 en que el puente del diablo por fin cedió. Aun quedan restos de la base del puente y se conservan fotos del puente en pie. Es recurrente en la sierra, escuchar narraciones en las cuales se cuenta que reunían a mendigos y/o borrachos en el lugar donde se iría a construir un puente de piedra. Se les invitaba una gran comida y en cuanto estaban gozando de ella se les arrojaban las piedras para comenzar con la construcción.
}

tuna.

Una tarde que estaban comiendo, Mariano perdió el apetito, su madre al mirarlo encontró esa mirada perdida que tienen aquellos a quienes les falta parte de su alma por algún amor o un anhelo.

"No abras tanto las piernas al comer, que así de anchos serán tus surcos en la milpa cuando seas más grande y vayas sólo a la parcela" le dijo su madre. Mariano cerró las piernas y arrimó su plato más cerca del banquillo de madera sobre el que estaba sentado, y poniendo su mano sobre el piso de tierra apisonada, justo a un costado de su plato de salsa martajada, le dijo a su madre: "Dice el maestro Hipólito que la tierra es de quién la trabaja". Su madre no respondió nada y se limitó a arrojar la mitad de una tortilla a un gato flaco y pardo al que llamaban Toribio, quién de inmediato la engulló.

Justo al amanecer y sin decir adiós a sus vecinos, recibió la bendición de su madre con el humo del copal y la silueta de los cerros que rodean a su pueblo. No dijeron mucho pero lo sabían todo, ella sólo esperaba que regresara algún día con bien; él sólo quería regresar con bien para darle una vida mejor.

Caminó mucho, más de lo que pudiera recordar. Tres noches y algunas veredas perdidas más tarde, encontró a lo lejos lo que en su mente le pedía a las estrellas en las noches obscuras recargado sobre sus brazos: la gran finca donde contratan a milperos por diez pesos el jornal. Era enorme, el puro casco era quizá más grande que su pueblo. Desde lo alto podían apreciarse las retículas de chilares, tabacales y platanares de la finca. Su mirada no alcanzaba a abarcar toda la extensión de las tierras cultivadas que se perdían entre los montes de las 
tierras bajas.

Caminó y caminó hasta acercarse al lugar. Antes de llegar, miró como unos peones golpeaban a otros labradores con lazos mojados y decidió resguardarse entre los matorrales. Una vez que los primeros se fueron, se acercó con acautela ante los exhaustos, intentando saber lo que ocurría. Con un acento bastante extraño pero en una lengua parecida a la suya, los labradores reprendidos le explicaron con el aliento entrecortado, que les habían golpeado por pedir el dinero total de su paga para poder regresar a sus pueblos.

Mariano quedó sorprendido, no sabía si por la golpiza que acababa de presenciar o por esa extraña lengua tan entendible para él pero muy diferente a la suya. Cuando los labradores por fin se recuperaron y lo escucharon hablar, soltaron carcajadas y le dijeron que hablaba como guajolote. Desde ese momento, ese sería su apodo: tajna ${ }^{6}$. A Mariano no le hizo mucha gracia pero estaba dispuesto a soportar ese pequeño incidente con tal de saberlo todo en torno al trabajo en la finca. Luego de terminar la jornada, los labradores llevaron a Mariano con ellos y fue presentado a un capataz que por cierto, le hizo el mismo comentario sobre su acento.

Luego de mirarlo, Mariano fue asignado a una cuadrilla de 27 mozos que estarían encargados de chapear y desmontar las tierras más lejanas de la finca.

Dormían en una barraca improvisada dentro de un secador de tabaco que no se usaba por el momento y comían tortillas cacalas $^{7}$, frijoles agrios, chiles cuaresmeños y agua. Recorrían largas distancias para

\footnotetext{
${ }^{6}$ Del totonaco: "guajolote".

${ }^{7}$ Tortillas tostadas o doradas.
}

cumplir con su tarea. El capataz de la cuadrilla les guiaba y les supervisaba en macho o a caballo y así fue por varias semanas.

Un día que Mariano miraba la luna al no poder dormir por un agudo dolor estomacal que le acosaba, un compañero le preguntó lo que pensaba en torno a la cuadrilla que habían dejado de ver hacía unos días. "El capataz dijo que se fueron a sus casas" respondió cortante. "¿Pero todos y al mismo tiempo?" replicó el compañero. A lo que Mariano remató "En cuanto junte un poco más voy a pedir mi dinero y me voy a ir a mi casa, si los del resto de la cuadrilla también lo quieren, nos iremos todos juntos".

Su compañero aguardó unos momentos de silencio y murmuró en tono obscuro: "dicen que a los que piden todo su dinero, los golpean y que si no aceptan lo que les ofrecen para irse, les mandan lejos con palas y los capataces vuelven sólo con las palas". A Mariano se le retorció el estómago más de lo que ya estaba, aunque no puso visualizar en su mente lo que eso significaba, pero no le gustó mucho la idea de que no le pagaran los diez pesos prometidos por jornal.

Pasaron más los días y Mariano se vio mermar en salud por lo que comenzó a arengar a sus compañeros para disolver la cuadrilla y pedir cada quién lo suyo. Cada día que pasaba, Mariano les iba metiendo en la cabeza esas historias que otrora el maestro Hipólito les dijera sobre "los latifundios", "las haciendas" y "las tiendas de raya". A Mariano le parecía que el modo en el que trabajaban esa finca era muy parecido a las historias del maestro Hipólito, así que envalentonado, seguía animando a sus compañeros para pedir lo suyo. Realmente creía aquello de que "la tierra es de quien la trabaja”. En el fondo estaba lejos de tener 
tintes mesiánicos y sueños revolucionarios; sólo anhelaba regresar a la casa su madre con todo lo ganado, comprarle un nuevo metate, muchas telas para ropa nueva y quizá una pareja de marranos.

Firme en sus convicciones, pensaba que sus compañeros estaban casi listos para acompañarle en su demanda hasta que, una noche de lluvia, unos capataces irrumpieron de manera abrupta en el secador y le sustrajeron a la fuerza, llevándolo a una troje cerraja junto con otros labradores. Por lo que pudo oír antes de que lo arrastraran, uno de sus compañeros lo había delatado y vendido por unas cintas de cuero nuevas.

Pasó la noche golpeado, hambriento y mojado. Trató de dormir aunque el estomago le dolía nuevamente. Al día siguiente les dieron de comer y de beber y armándolos con palas. Les indicaron que irían a rascar un abrevadero para las vacas en un potrero lejano. Durante su camino, tres capataces a caballo les escoltaron. Ellos eran 14 mozos e igual número de palas. No llevaban alforjas ni viandas, solo las palas.

Por más que lo quería evitar, Mariano no dejaba de pensar en lo que aquel jornalero le dijo sobre las palas y sobre aquellos que pedían su dinero completo. Entonces comenzó a fingirse el enfermo y a retrasarse notoriamente del grupo. Al percatarse, los capataces lo reprendían y lo azuzaban con el caballo, pero como ciertamente tenía algún problema estomacal, no dudaba en demostrarlo con algunas flatulencias y gestos de profundo dolor y encogimiento.

Siguieron caminando bajo el sol y cuando escuchó decir que ya estaban cerca, fingió un par de desmayos. Los capataces le asignaron su pala a otra persona y nuevamente lo arengaban a caballo para que continuase.

Mariano insistió que necesitaba beber algo y que había visto un ojo de agua no muy atrás de donde se encontraban, uno de los capataces le dijo al otro que le convidara de su agua a lo que respondió de inmediato con un gesto grotesco y una frase irónica: "este ya viene moribundo, déjale algo a los zopilotes" y rieron a carcajadas.

Justo cuando sintió que lo iban a matar, Mariano sólo quiso recordar la silueta de los cerros que delineaban su pueblo y el olor a copal quemado con el que su madre lo había limpiado y bendecido ese amanecer en que decidió dejar Kalaxuxne para buscar diez pesos por jornal en esa tierra lejana.

Los capataces se juntaron lejos de él, que yacía en el piso con gestos intensos de dolor, y platicaron unos momentos. Luego regresó uno y le dijo: "si no regresas pronto voy por ti y te hecho al caballo encima". Mariano no mostró satisfacción alguna y solo miró de reojo al resto de los catorce mozos que adelante aguardaban cansados.

Luego de unos pasos a rastras, Mariano se incorporó para caminar con dificultad en aparente dirección al ojo de agua que habían visto no mucho tiempo atrás, pero en vez de dirigirse a este se fue ladeando, dando tumbos, con rumbo hacia el monte. Con paso lento y andar paciente se fue introduciendo en el monte. Una vez que los perdió de vista corrió tan rápido como pudo y cuando sintió que estaba lo suficientemente lejos se arrojó entre unos arbustos enramados y trató de cubrirse totalmente con hojarasca y basura de monte. Una vez ahí casi dejó de respirar, no le importaba que el chichicaxtle $^{8}$ le quemara la cara o que las hormigas le comenzaran a quemar las piernas con sus mordeduras. Sin importar lo que pasara, Mariano no pensaba moverse ni

\footnotetext{
${ }^{8}$ Ortigas venenosas.
} 
para respirar.

El silencio del monte con sus arrullos de viento y los gritos de los insectos le estaban matando lentamente. Aun así no se movió.

Solo tiempo después pudo oír a lo lejos, la escaramuza que los caballos causaban al jinetear con velocidad de un lado para otro. Tiempo después dejó de escucharlos. Pasó más el tiempo y nada cambiaba en su postura hasta que, cerca del atardecer pudo escuchar con dificultad el tronar de balazos que se perdían en la espesura del monte. Aunque no quiso moverse, el sonido de aquello lo hizo sobrecogerse por las rodillas como cuando había llegado al mundo y quedarse inmóvil y despierto toda la noche. Una vez que vio a la pálida luna con la forma de cuña sobre si, se levantó y corrió rumbo a su tierra tan rápido como sus fuerzas se lo permitieron. Fueron muchas las veces que tropezó por la obscuridad y mucho el dolor que se infringió en su frenética carrera.

Para el resto, sólo basta decir que las tres noches de camino hacia el río Cempoala se convirtieron en dos y estando a la orilla del mismo, quiso descansar un poco más al anochecer, pero no lo consiguió. Como pudo y cual si fuese un ladrón, regresó a su pueblo tratando de esconder los rastros que dejaba a su paso hasta que exhausto, enfermo y lastimado pudo mirar la silueta de los cerros que delineaban su pueblo y el olor a copal quemado con el que su madre lo había limpiado y bendecido ese amanecer en que decidió dejar Kalaxuxne para buscar diez pesos por jornal en una tierra lejana. Mariano se prometió nunca más salir de su pueblo, cosa que ha cumplido al pie de la letra y jamás contó su historia hasta la muerte de su madre muchos años después. Ahora sólo espera reunirse con ella y poder- se mirar una vez más en los ojos de aquellos, que junto con él, formaban la cuadrilla de 14 mozos que nunca volvió a ver.

\section{NOTAS SOBRE LA CONSTRUCCIÓN DE LA MEMORIA Y LA HISTORIA ORAL}

La historia de vida de Mariano es el referente ideal para la reconstrucción de la migración laboral en el Totonacapan. A partir de su primera migración como jornalero y todo el periodo en el que fue arriero, vivió una serie de sucesos desde los cuales podemos acercarnos al pasado de la región, para ello es necesario contar con las herramientas adecuadas y la paciencia necesaria para ir comprendiendo los diferentes momentos en que vio cambiar los pueblos y que con dificultad, narra en su lengua materna.

Paul Thompson (1988) en La voz del pasado, nos dice que "la historia oral devuelve la historia a la gente con sus propias palabras" y es esto lo que intenta el trabajo propuesto.

La afirmación anterior nos obliga a reflexionar en torno a la pertinencia del uso de la tradición oral como fuente histórica y comunicativa, la cual, se tambalea entre los mitos y las realidades pasadas, dificultándonos como investigadores sociales, asir el pasado no documental de una manera clara. Por su parte la etnohistoria nos da la posibilidad de abrirnos a fuentes diversas que toman en cuenta a aquellas personas y sus colectivos, sobre todo a aquellos que no han elegido la opción del registro escrito para plasmar su continuidad en el devenir de los años, sin embargo, el trabajo con estas fuentes es mucho más delicado de lo que pareciera y nos puede llevar por caminos muy obscuros y difíciles de atravesar 
con éxito.

Trabajar con la tradición oral y los relatos orales desde la disciplina de la comunicación, dándoles coherencia, cadencia y legitimidad para poder construir el pasado, no es fácil, sin embargo es un reto tan maravilloso como lo es reconstruir una ciudad que quedó en escombros luego de una guerra o un desastre natural. Para este trabajo, no sólo nos basamos en las descripciones de los sujetos de la región, sino en referentes documentales así como en la etnografía basada en el trabajo de campo y la observación participante, para obtener el mejor resultado posible. De antemano sabemos que es mucho más común dejar los relatos orales a los literatos o los estudiosos del folclor, sin embargo desde la comunicación intercultural y la comunicación para el cambio social, podemos trabajar todos aquellos elementos comunicativos que nos ayuden a comprender mejor la realidad para trazar líneas concretas de apropiación y reconstrucción de la memoria para una mejora en la calidad de vida.

Darle un lugar en la memoria social a lo que la gente sabe, cree que sabe y lo que cree que no sabe a partir de los relatos orales, es una de las tareas del comunicólogo contemporáneo y desde luego es uno de los objetivos de este trabajo al tratar de reconstruir la memoria, el espacio y la cotidianidad en el Totonacapan, a partir de la lengua originaria, para la segunda mitad del siglo $\mathrm{XX}$.

Una de las peculiaridades de los métodos de investigación que se impusieron en la segunda mitad del siglo XX es que se consideran actores ignorados por la historia tradicional, como las minorías étnicas, campesinos, obrero u otras minorías. Hoy día, muchas investigaciones se dedican a indagar en torno a fenómenos relacionados con los campesinos, la familia, la mujer como grupo social, la diversidad sexual, la moda, la cocina, etcétera. Estos nuevos campos de estudio provocaron la revaloración de los testimonios y documentos verbales. No es lo mismo escuchar el relato de las dificultades campesinas en las regiones cafeticultoras ante la caída del precio del café, en palabras de quien lo ha vivido, que leer un artículo periodístico sobre ello. Debido a esto, se prestó mayor atención a los recuerdos, experiencias y puntos de vista de los testigos y actores del acontecer contemporáneo y la historia reciente.

Es en los testigos que no se ven a sí mismos como dignos de ser tomados en cuenta, donde la comunicación intercultural y para el cambio social ha puesto cada vez más su atención, con ello se recuperó la vieja práctica de los pueblos indígenas, de transmitir la información de padres a hijos o las costumbres ancestrales, costumbres de Tucídides y Herodoto al preguntar a la gente lo que vio y lo que conoció, la diferencia es que ahora poseemos medios tecnológicos más avanzados para registrarlo y tenemos referentes teóricos y conceptuales más ricos que nos ayudan a tratar las fuentes orales con mucha rigurosidad.

No fue sino hasta hace cuatro décadas cuando diversas disciplinas como la literatura, la sociología, comunicación y la misma antropología, comenzaron a tener intereses en los testimonios orales, en especial los llamados autobiográficos, sobre todo de personas que no figuraban entre destacados sujetos de la sociedad sino de ciudadanos comunes o como solemos llamar, la "gente de a pie".

Fue entonces cuando surgió una escuela que tiempo después se le nombró como 
Historia Oral. Hasta este entonces nos dice Barthes: "La historia era una memoria fabricada según recetas positivas, un puro discurso intelectual que anulaba el Tiempo mítico" (BARTHES, 2007, p. 144)

Durante las primeras décadas del siglo XX, se dieron muchos cambios en torno a los fenómenos de estudio del pasado, sobre todo en el campo de la Historia Social, se dio un renovado escalafón en la importancia de los sujetos en los sucesos públicos: los heroicos personajes que ganaban batallas y lograban glorias casi por si solos se quedaría en las versiones oficiales o en la Historia del siglo XIX y sus predecesoras. En adelante, los actores sociales "anónimos" incluyendo las minorías o los antagonistas tomarían una nueva relevancia. Por otra parte, las nuevas tecnologías que permiten registrar sonidos y voces contribuirían a recabar los relatos orales, que antaño sólo podían ser recabados por escrito, lo cual requería de grandes habilidades en dicho menester o de escribanos profesionalizados en esas tareas, sobra decir que esto resultaba muy complejo y en no pocas ocasiones carente de confiabilidad.

Otro elemento interesante es que estas nuevas tendencias no sólo contemplaron a los relatos orales sino que incluyeron otra gama de fuentes que enriquecerían los estudios de los nuevos sujetos protagónicos en la historia así como de la vida cotidiana de ellos y sus comunidades, como lo afirma Di Marzo al decir que

Los testimonios de protagonistas más o menos anónimos no fueron las únicas fuentes que comenzaron a tenerse en cuenta. También se incluyeron en esta categoría cartas, diarios íntimos, o fotos familiares, o todo aquello que registrara de al- guna manera la vida cotidiana. (DI MARZO, 2005, pág. 170)

\section{Por su parte Edward H. Carr afirma que}

La historia es, en términos generales, un recuento de lo que han hecho los hombres y adquiere significado y objetividad sólo cuando establece una relación coherente entre el pasado y el futuro [...] Los datos de la historia no pueden ser puramente objetivos, ya que se vuelven datos históricos precisamente en virtud de la importancia que les concede el historiador. La objetividad en la historia -si es que podemos seguir utilizando este vocablo convencional-, no puede ser una objetividad del dato, sino la relación entre dato e interpretación, entre el pasado, el presente y el futuro. [...] La historia llamada así con propiedad sólo puede ser escrita por los que ven y aceptan en la historia misma un sentido de dirección. La convicción de que provenimos de alguna parte está estrechamente vinculada a la creencia de que vamos a algún lado. Una sociedad que ha perdido la fe en su capacidad de progresar en el futuro dejará pronto de ocuparse de su propio progreso en el pasado. [...] Nuestra concepción de la historia refleja nuestra concepción de la sociedad. (CARR, 1999, pp. 184-199)

Aquí es donde encontramos la coyuntura ideal para este estudio entre los elementos: historia, espacio, tiempo y sucesos. El espacio es un producto histórico en movimiento y cambiante a través del tiempo y nuestro espacio en particular se encuentra inserto en la región del Totonacapan. Para el abordaje del espacio social y el territorio, los planteamientos de Milton Santos y de Gilberto Giménez representan una herramienta pertinente en la cual nos hemos apoyado 
con firmeza

Por su parte Santos nos dice que:

El espacio debe considerarse como un conjunto de relaciones realizadas a través de las funciones y de las formas que se presentan como testimonio de una historia escrita por los procesos del pasado y del presente. Es decir, el espacio se define como un conjunto de formas representativas de las relaciones sociales del pasado y del presente, y por una estructura representada por las relaciones sociales que ocurren ante nuestros ojos y que se manifiestan por medio de los procesos y las funciones. (SANTOS, 1990, pág. 138)

A lo que Giménez añade:

El concepto de territorio o territorialidad es muy importante para entender las identidades sociales territorializadas y las de los grupos étnicos además de servir para encuadrar adecuadamente los fenómenos del arraigo, del apego y del sentimiento de pertenencia socioterritorial, así como los de la movilidad, los de las migraciones internacionales y hasta los de la globalización. (Gimenez, 2001, pág. 6)

y continua diciendo:

Se entiende por territorio "el espacio apropiado y valorizado por un grupo social para asegurar su reproducción y la satisfacción de sus necesidades vitales" Se trata de un concepto multiescalar que puede ser aprehendido en diferentes niveles de la escala geográfica (Gimenez 2001, pág. 5) Dichas necesidades pueden ser materiales o simbólicas.(Gimenez, 2001, pág. 6)

Finalmente, consideramos que no es posible abordar la reconstrucción de la memo- ria de los grupos sin tradición escrita, sin dar la palabra a aquellos que nunca la han tenido, pero tampoco es posible compartir dicha memoria en otro marco cultural, sin la intervención del investigador el cual, deberá hacer con el cuidado de un relojero suizo o un cirujano oftálmico, ese hermoso pero delicado ejercicio de la traducción cultural.

De manera personal, tengo la esperanza de que la confianza de Mariano y tantos otros, depositada en nuestras entrevistas y grabaciones, sirva para contribuir al acercamiento y reconstrucción de la memoria y la cotidianidad entre los totonaco; para que las generaciones actuales y las venideras puedan comprender el pasado que sustenta su presente. Hasta entonces, no nos queda más seguir nuestro trabajo, esperando que los que vengan después, puedan explicar lo que nosotros hacemos para entender sus propios presentes y trazar un futuro en el que todos tengamos la posibilidad de hacernos escuchar.

\section{REFERENCIAS}

BARTHES, Ronald. La Cámara Lúcida. Notas Sobre La Fotografía. Barcelona: Paidós. 2007.

CARR, Edward H. ¿Qué Es La Historia? Barcelona: Ariel. 1999.

DI MARZO, Laura C. Una Araña En El Zapato. In Una Araña En El Zapato. Buenos Aires: Libros de la Araucaria. 2005.

GIMÉNEZ, Gilberto. Cultura, territorio y migraciones. Aproximaciones teóricas Alteridades, vol. 11, núm. 22, julio-diciembre, 2001, pp. 5-14 México: Universidad Autónoma Metropolitana Unidad Iztapalapa. 2001.

SANTOS, Milton. Por Una Geografía Nueva. Madrid: Espasa Universidad. 1990. 
THOMPSON, Paul. La Voz Del Pasado. Historia Oral. España: Edicions Alfons el Magnànim / Institució Valenciana D’estudis i Investigació. 1988. 